\title{
The Grit in the Oyster - does an appreciation of threshold concepts in an adult literacies teaching qualification result in pearls of practice?
}

\author{
DAVID WALLACE
}

(From a paper presented at the Australian Council for Adult Literacy Conference (Surfers Paradise) - October 2-4 2008)

\begin{abstract}
This paper draws from the experiences of a new adult literacies teaching qualification in Scotland that has been designed for experienced but unqualified adult literacies tutors. Created to respond to an approach to adult literacies as social practices (Scottish Executive 2001, 2005, Tett et al 2006), the course team employs a sociocultural pedagogy that explicitly rejects transmission and seeks to build critical reflection through learning from experience, collaborative activities and the creation of an on-line community (Ackland and Wallace 2006). Recognising that 'moments of conflict and disjuncture may form the spaces in which learning occurs' (Lewis, Enciso and Moje 2007:5) the paper explores whether ideas about liminality and threshold concepts (Cousin 2006:1, Land, Meyer and Smith 2008) illuminate the learning process. It concludes that engagement with these concepts may assist adult literacies tutors to develop transformed practice (Cope and Kalantzis 2003:35).
\end{abstract}

\section{A Pilot Teaching Qualification in Adult Literacies (TQAL)}

The first students in Scotland to have undertaken a part-time course to obtain a teaching qualification in adult literacies graduated in November 2008. The course lasted 20 months and was undertaken by experienced literacies tutors from around Scotland. Drawn from a range of statutory and voluntary organisations these literacies tutors operate in diverse settings and with a wide range of terms and conditions of employment. Being fully funded by the Scottish Government, the program was designed as a pilot to meet policy priorities regarding the professional development needs of adult literacies tutors (Scottish Executive 2001).

The pilot program has been developed by a consortium of partners including Universities of Strathclyde, Aberdeen, and Dundee; Cardonald and Forth Valley Colleges of Further and Higher Education; the Scottish Further Education Unit; and practitioner representatives, one from Highland Council and the other formerly of the Workers Education Association.

The professional requirements of the qualification were published in benchmark statements drawn up by the Quality Assurance Agency and 
Learning Connections in 2005 specifying a qualification that could be offered at two levels - a Bachelor of Arts degree or Diploma of Higher Education. Required to be accessible to tutors across Scotland, the course has been offered in four study centres around the country. The program started in January 2006 with forty-eight students. Thirty-three students have now completed the course that encompassed engagement with four sequential modules each worth 30 credits and each with 300 hours notional student effort. In summary the four modules are:

1 Learning Worlds: Exploring the diversity of socio-cultural learning experience and addressing aspects of informal learning, situated learning and aspects of professionalism;

2 Making Mental Models: Exploring the evolving stories of literacies, learning and education through a variety of lenses (e.g. sociological, psychological, and philosophical). Theoretical perspectives form a means of critical engagement with and understandings of practice;

3 Expanding Our Repertoire: Working on the basis that no clear consensus exists about the best ways to develop reading, writing and mathematical concepts, practitioners will build a repertoire of strategies for particular purposes, on which they can draw creatively in the specific situations they encounter;

4 The Enabling Net: This module further contextualises literacies and learning. Exploring the concept of the activist teacher, participants explore the need for comprehensive networks, partnerships and activism among literacies tutors.

The program involved regional groups of students coming together in study blocks for each module (each of a week in duration); undertaking workbased learning in which the principles of the program are explored in literacies practice; and engaging with a virtual learning environment (VLE) to scaffold learning in each module, linking students with their peers and actively encouraging dialogue and collective reflection through an on-line community.

Assessment is designed to be sustainable (Boud 2000) in that there is a strong formative component - through tutor comment on on-line contributions, through on-line tutorials and through observed practice. These forms of assessment fit with social practice thinking (Green and Howard 2007:18) and are central to the principles for learning on the program. There are a range of assessments including a case study, a professional development plan, a literature review, a presentation on an ethnographic study undertaken with learners, and observed practice reports.

Complementing the work of students studying for the adult literacies teaching qualification, a group of experienced practitioners operate as practice tutors to offer professional guidance and mentoring to students with whom they are paired. Supporting learning through observation, dialogue and reflection on practice, this group of practitioners has also contributed to 
the ongoing evaluation of the pilot and to testing the principles of the program.

\section{The TQAL stance}

In Colin Kirkwood's (1990:11) collection of essays he begged questions about whether we, personally or communally, could influence the shape of the future; or whether this was not possible since we are determined by forces beyond our control. The pilot program of which I write is permeated with a conviction that we can influence the future personally and communally through critically informed adult literacies practice.

The starting point for this stance is the social practices ethos that informs adult literacies in Scotland - one that affords the potential to engage with adult learners on everyday matters that are of interest or concern to them. A key purpose of the literacies tutor in a social practices approach is to uncover and understand everyday uses of literacy and numeracy over 'schooled ways of knowing' (Papen 2005:129). This is extended by our choice of a framework for teaching and learning that is deliberately socioconstructivist (De Corte, Vershaffel, Entwhistle and van Merrienboer 2003:25) and in which the student identity and experience is the foundation for our engagement with them. It is from these starting points that we then draw from and interrogate a canon of literature on the repertoires required for the teaching of reading, writing, assessment, numeracy and information and communication technologies (ICT). This constructivist approach is in turn advanced by a systematic approach to building critical reflection (Moon 2006). In our selection of an anthropological epistemology for learning (over more traditional psychological paradigms), our approach aims to develop a community of practice to build and to capture aspects of collaborative learning. To build social knowledge we wanted to move beyond the individual approach to reflection to embrace the experiences of the community of participants. We aimed to maximise opportunities for interaction between adult literacies practitioners as students 'in ways that interlock their stakes in histories of practice' (Wenger 1998:276).

We agree further with Wenger (1998:277) that if 'learning is a matter of identity, then identity is itself an educational resource'. This is therefore a professional development program for literacies tutors that explicitly engages with their identity as a means of grounding learning through exposing and critiquing tacit knowledges, creating foundations for new understandings and affecting new knowledge and new practice. Contrary therefore to a trend toward education being transformed into training, we have consciously avoided transmission models in our approach to continuous professional development (CPD) and have sought to open up the requirement for students themselves to consider metacognition - to think more, question more and practise more as means to initiating transformation of their identity 
(Brookfield 2000:89-100). We require students to build an understanding not only of the repertoire required for adult literacies practice but also to appreciate and engage with what Kirkwood (1990:11) termed 'the forces beyond our control' - i.e. the hegemony, ideologies and structural inequalities that shape and influence our lives and the lives of the literacies learners with whom we are engaged.

The process encouraged me to challenge my own ideas about the way we do things and why. It also made me re-evaluate my own understanding to be more in tune with practical application of policy against its theoretical assertion. [Student Comment]

Following Moje and Lewis (in Lewis, Encisco and Moje 2007:46) we were concerned to '....uncover the positions students are willing to take up and the agency they have to resignify, disrupt or examine prevailing discourses' for deeper literacies learning. These foundations for professional development may not necessarily have been familiar to participants prior to the program. As a consequence our methods presented both additional and critical dimensions for learning and a challenge to the course team as we sought to adhere to an untested and new set of principles that we aimed to constructively align (Biggs and Tang 2007). Although drawing from contemporary literature to inform this stance there is, never the less, an acknowledged experimental dynamic in the program. To the extent that we also adopt a blended learning strategy to enact these pedagogical principles (including a mix of study-centre, work-based and on-line learning) there is a departure from the framework of disciplinary study at university to develop new pedagogies for learning (Boud, Solomon and Symes 2001:4). Central to our design are the following core principles:

- The overall process of learning is built on a framework of curriculum design in which intended learning outcomes, teaching methods, and evaluation are all interdependent and only by truly integrating these components together, do we achieve efficient student learning (drawing from Biggs and Tang 2007);

- $\quad$ Staff involved in teaching must themselves commit to a reflective practitioner approach to their work and be prepared to learn from their mistakes and successes (drawing from Cranton 2006, Moon 2006, Brookfield 2000);

- Meaning is not imposed or transmitted by direct instruction-it is created by the student's own learning activities (drawing from Eraut 1994, Engerstrom 2001, Cheetham and Chivers 2001, De Corte et al 2003). 
As a foundation for enacting these principles, professional enquiry and action learning are features across modules. The intention is to keep the practitioner/student and their experience at the centre of the pedagogical model, raising awareness amongst them of the potential to learn lessons together and to disseminate good practice by means of research. This acknowledges the grounded experience of the literacies tutors whilst seeking to develop new aspects of learning and the construction of new knowledge. We concur therefore with Howard (in Davies, Hamilton and James 2007:5) who notes in her foreword how practitioner research '...encourages critical and reflective enquiry...throws light on, explores and challenges accepted practices and received wisdom from the inside as well as the outside'.

\section{The framing of professional development for adult literacies tutors}

Although there is an ambitious vision for adult literacies through the social practices approach in Scotland, our experience suggests a number of tensions within and between policy, management and practice (Maclachlan 2006). These may be expressed in the form of conceptual dualisms - a continuum on which there are opposing positions at the extremities e.g. functional literacy models and critical literacy models (Papen 2005) or managerial professionalism and democratic professionalism (Sachs 2000). These continuums may be visualised as professional barometers with an indicator needle that fluctuates and is positioned somewhere between one or the other extreme depending on prevailing influences on practice. The framing of practice is therefore contingent and variable. Practice norms vie for prominence in the context of pressure from dominant discourses routinely around functional models and much more rarely around critical models of literacy. Thus adult literacies tutors in their practice may encounter and experience taken-for-granted operational arrangements - in agencies in which routines of practice are pre-configured (particular groups meeting in particular places using particular teaching methods); in the way that planning takes place at a macro and managerial level (routinely at some distance from the literacies tutors); and in the processes of management, audit and inspection (in which the returns required for stakeholders and funders can tend to be data rather than learner centred). The voices of adult literacies practitioners, who are often in the weakest positions within their various organisations, may not be supported by the language of policy that is routinely interpreted and filtered for them by those in positions of authority and hence presented as a given. Under such conditions the space for adult literacies tutors to critically engage with policy, in the light of their experiences as practitioners, may be limited or off-limits. 
This position is consistent with research into the Scottish adult literacies strategy through which Tett, Hall, Maclachlan, Thorpe, Edwards, and Garside( 2006) commented that those with most contact with learners tend to be those on part-time contracts and with little access to support and training. We are mindful, therefore, that the practices we as teachers see as meriting analysis and change are largely configured through relationships of power and ideological hegemony (Moje and Lewis in Lewis, Encisco and Moje 2007:17), an appreciation of which is crucial to understanding the milieu in which the adult literacies tutor is located. Whilst we subscribe to the community of practice as a model for social and collaborative learning, we have learned that a contradiction in the model is that legitimation of knowledge - legitimate peripheral participation (Wenger 1998) - is moderated not simply by the efficacy of the knowledge or new ways of doing something, but may be dependent on who created the new rule or knowledge:

...certain types of knowledge and understanding might be privileged or inhibited, encouraged or prevented not on the basis of work practice knowledge, but on the basis of status and power. (Saunders 2006:17)

Although we are reminded of the dangers of placing too much emphasis on agency and the potential of individual employees to enact change, this scenario resonates with the tensions identified by Sachs (2000) in teaching discourse in Australia between democratic professionalism and managerial professionalism. Agreeing with Sach's (2000) exposition of trust and reciprocity as central characteristics of democratic professionalism, we have subsequently endorsed her conception of the activist teacher throughout the TQAL program.

Whilst we sought to tailor the program to balance institutional, employer and individual learning goals, at the outset we defined pedagogical principles consistent with an aspiration to a social practices view and have avoided compromising this position. Although these principles are authoritatively promoted (largely as a result of our privileged position in the academy), feedback suggests that in some quarters they may be received as radical or even esoteric. This reaction may be underpinned by what Maclachlan (2006:32) identifies as dissonance in Scottish policy and practice between the ideological model of social practices and the employability imperative. The tension here is between instrumental approaches to learning and more associational, creative and expressive approaches to learning. Our position of sticking to the principles of an aspirational discourse meant therefore that we contested the experience of other stakeholders including some employers (and some participants on the program) whose reality is 
shaped by literacies discourses that may be inconsistent with social practices approaches.

It cannot be taken for granted, therefore, that adult literacies practitioners and prospective students will readily subscribe to notions of learning expressed as functions of reflexivity, collaboration or action enquiry. For many of them, problems may be subjectively important, set in a particular social context of employment through which learning may be shaped by expectations that reside in already established experiential patterns (Illeris 2007:255). Indeed participants on the TQAL program, shaped by these social relationships at work, may hold to a view of Higher Education as expert instruction and anything which does not conform to these preconceptions may be regarded as inferior and second rate (Hagar 2004).

Although we see the work community as an important learning environment, the informal learning processes of work communities have been described as under-researched and remaining obscure (Collin and Valleala 2005:401). Whilst our approach has been predicated on new literacies studies, social practices and the sociological and anthropological lenses afforded by authors such as Eraut, Alderton, Cole and Senker (1998), and Wenger (1998), it may be the case that what is learned in the workplace remains partial and personalised, subject to the limitations of agency. It may also continue to be shaped 'by past habits and routines...and by the contingencies of the present moment' (Evans and Kersh, 2006:2-3).

The interesting question, then, is what assumptions underlie our tacit decisions to use or not use certain activities and tasks with learners. And what does this tell us about our theory of learning and teaching writing.? [Student Comment on VLE]

We agree with Wenger, McDermott and Snyder (2002:9) who identify with embodied expertise that may reside in tacit knowledge. However the social aspect of knowledge development may equally have the potential to be corrupted through institutional, structural or cultural norms. The adult literacies tutors who have embarked on our program are products of a set of cultural norms and values framed by Scottish adult literacies policy and filtered through the variety of domains and contexts in which such practice takes place. It is no surprise that, for many, their intuition - viewed as a product of identity, prior learning, tacit beliefs, assumptions and values may, as Claxton (2000:42) attests, be fallible. Their intuition may derive from limited knowledge and narrow experience; non-reflexive observation and unchallenged assumptions - the embodiment of a pre-liminal state set out by Cousin (2006:1) and others that I will revisit in the next section of the article.

Although more accepting of core pedagogic principles as the program progressed, we encountered reaction from some students (and from some practice managers) to the effect that the collaborative and group learning 
approach was not what was anticipated - i.e. it was not instruction and did not conform to expectations about 'lectures' and input by 'experts'. Our rationale for the program, however, was informed by an understanding that adult-literacies tutors operate in diverse settings and with a wide range of cultural networks and situated knowledges. In such circumstances, seeking to apply one key system (if one indeed existed) would not be appropriate or meaningful given the range of contexts, experiences and cultures that literacies tutors encounter. This is therefore a core site for critical reflection and learning that requires the nurturing of dialogue and conversation through which presuppositions, ideas and beliefs and feelings can all be made explicit and available for exploration (Hakkarainen, Palonen, Paavola and Lehtinen 2004). In such circumstances it was recognised that we cannot teach everything that must be known and that we were required to account for dynamics of practice which are evolving and unfolding. Our concern therefore has been to create a space, both real and virtual, in which knowledge is treated as being in design mode (Bereiter and Scardamalia 2003:55) and through which participants working together are encouraged and supported to be reflexive, enquiring and creative. Our intentions on the program align with Earl and Timperley (2008:22) who observe that 'the merging of the process of deep collaboration with evidence and inquiry can create the conditions for generating new knowledge'. We further concur with Cranton (2006:182) who argues that technical knowledge about teaching cannot be overlooked but that 'technique should not drive an educator's perspective of practice, rather a perspective on practice should determine what technical knowledge is required'.

Typically, adult learning, of which continuous professional development is one domain, may be viewed as a function of identity. Wenger (1998:215), advancing this idea, described it as a process of becoming or avoiding becoming a certain person. Such learning may therefore be selective and sceptical or may result in active resistance, defensive rejection, blocking or distortion (Illeris 2007:255). It is to this area of troublesome knowledge (Meyer and Land 2006) that I now turn to provide an analysis of how the ideas of liminality and threshold concepts (Land, Meyer and Smith 2008) may assist in providing insight into the process of professional development and learning within the program.

\section{Liminality as a necessary condition for professional development}

In many individual cases, learning for participants appears to have been transformational. However, from student dialogue and reflection we are aware that this is not always an enjoyable or comforting experience. Learning in this way may be troubling, may result in unexpected outcomes and may provoke a state of stasis if the learner resists or is disinclined to move through 
transition to transformation. It is common parlance among the students to define the learning process in relation to the comfort zone and, consequently, to stepping out of the comfort zone.

We ask learners to go outside their comfort zones in their learning - without this it is difficult to progress - - so why should we not be pushed outside ours? And it's good to see how this feels (on reflection of course!) and be reminded of how valuable it is to face challenges. [TQAL Student Comment]

I have theorised, therefore, that it is these pivotal moments of uncertainty, contestation or resistance, associated with moving from the comfort zone, that may be construed as the locus for creative tensions - a liminal stage in reflection at which there is a nexus for learning. Arguably, it is these contested or uncertain spaces - the stage of liminality (Meyer and Land 2006:2) - that are true sites for professional development for the participants. These stages provide a locus for reflection, analysis and dialogue resulting in the participant either dwelling in an existing, if questioned, knowledge space or departing to a new way of knowing.

A pre-liminal stage may also be theorised, one that occurs prior to the student's encounters with other people in a community of practice and with other ideas about what constitutes practice. Mastery of the threshold concepts (Land, Meyer and Smith 2008) in our sociocultural pedagogy may at this stage be inhibited since they may seem to a student to cut against common sense or intuitive frames of reference to which they hold dear. Cousin (2006:2) subsequently posits that getting students to reverse their intuitive understandings is also troublesome because the reversal can involve uncomfortable emotional repositioning.

The general point I am making, however, is that having reached a stage of awareness on the program through a combination of experience, dialogue, reading and collaboration with others, neither the dwelling nor the departing are necessarily comfort zones. The state of liminality will be experienced differently by every student but represents a zone beyond which the impact of reflexivity cannot be readily set aside. Meyer and Land (2003:4) reinforce this irreversibility and equate the mastery of threshold concepts with deep and long lasting learning. However the move out of the comfort zone may connect, in the student's reaction at these stages, to what Brookfield (2000:9699) identified as the loss of innocence and sense of impostership - stages in identity transformation that are problematic and that require careful support and nurturing from teachers and peers. The engagement with liminality and threshold concepts would appear therefore to be central concerns for this program if we are to seek the most effective and powerful forms of learning.

In going forward we want to challenge as Brookfield says those ideological toxins that are deeply embedded both within our 
institutions of learning and in us. By so doing we will challenge accepted practice, inform policy and be more effective in reaching those who require the most help. [Student Comment on the VLE]

In Freirean terms this process may be equated with the journey from naïve consciousness to an emerging critical consciousness (conscientisation) and, when articulated through informed action, to praxis (Freire 1972). Sommerlad (2003:157) contends that what one learns and how it is learned cannot be separated from the groups one belongs to, nor from their wider location in the social structure. For some students on the program however, the experience of critical reflection on adult literacies has seen them question their place in existing work communities- - a situation that may find them at odds with previously comfortable and supportive work relationships. Such powerful learning, in realigning identity, may be emotionally charged and we concur therefore with Sachs (2003:31) who notes that learning for teachers has personal, professional and political dimensions.

We will all take many positives from our TQAL experience I am sure but the most positive aspect for me is that we are more active in our practice, more critically aware of how and why we practice and apply more critical analysis to our profession.

[Student Comment on the VLE]

As Cousin (2006:1) attests 'new understanding is assimilated into our biography, becoming part of who we are, how we see, how we feel'. It appears that the experience of being on this program may lead some to a transition stage at which the student/practitioner will reconsider, reconfigure or exit a community of practice. The powerful role of identity in learning is again embodied in these propositions. It may be constructed 'to include different meanings and forms of participation into one nexus' (Paechter 2003:75) and developing as multimembership (Wenger 1998:159). Once we adopted the constructivist paradigm for professional development it could be argued that certain concepts - social practices, critical reflection, metacognition, collaborative learning and constructivism - became threshold concepts (Meyer and Land 2006) that are central to the mastery of our subject (adult literacies learning). For some students the experience involved troublesome knowledge and the oscillating back and forth between previous and emergent understandings (Cousin 2006) and between previous and emergent identities. It has therefore been our intention to structure the virtual learning environment in such a way that the students could save and exchange material and navigate back and forth between current and earlier modules. The shared areas on-line provide a repository of ideas that could be revisited and revised throughout the program. The VLE became an important open channel to the wider community of practice; a mechanism for 
providing a sounding board and access to critical peers that could support transitions. In this respect the VLE potentially offers a forum and a number of guides to assist in navigation through the experience of liminality.

I strongly feel that the VLE was a major asset to this course. The ability to interact with both fellow students and our tutor on an almost daily basis removed much of the feelings of isolation that I had experienced on a previous part time degree course. The blog element allowed us to discuss not just within a specific course subject viewpoint but as a social 'meeting point'. The file sharing and website exchanges made the research elements of assignments highly effective. [Student Comment on the VLE]

\section{Pearls of Practice?}

Theorising about the applicability of threshold concepts and the experience of liminality assists in understanding the experience of professional learning for adult literacies practitioners on this program. These concepts may also have applicability for continuing professional development in other professional areas such as further education, social work, community work or youth work. The articulation of core pedagogical principles and their assertion through action inquiry, literature and modelling in practice appear from our experience to create powerful learning environments (De Corte et al 2003) through which transformation may be attained.

Kirkwood (1990) posited a question about the degree to which we can shape the future (in adult literacies) and outlined the notion that we are determined by forces beyond our control. In reflecting on the principles and analysis encountered in this article I am reminded of his caveat: unless.

We are determined unless we take on the task of knowing ourselves, that is to say both the inner potential self, and the self that we have become through our responses to environmental impingements. We are determined unless we take on the task of knowing our context, the interacting forces and themes of our society and the world as a whole. We are determined unless we make a move from an orientation of passivity to one of reflective engagement. This can only be done in collaboration with others. But we cannot genuinely collaborate unless we seek to know ourselves. The personal and the communal are not alternatives: they are co-essential dimensions of human emergence. (Kirkwood 1990:11)

The design of the Teaching Qualification in Adult Literacies appears to meet these ideals. Though the experience of all students on the program cannot be generalised there is sufficient evidence to suggest that the course has initiated a potentially regenerative learning process - a process of 
transformation that may continue beyond the conclusion of the TQAL course.

As 'professionals' I feel we need to keep stretching the boundaries, doing the requirements of the job but always, always broadening this out to include a critical analysis of what we are doing, why and in whose interest. If we don't challenge these and put forward alternative visions then we are not active participants in anything, we are merely deliverers of governmental economic policy and we limit not only what we do but what literacies are!

[Student Comment on the VLE]

We in the consortium know that there remain lessons for us to learn from the TQAL pilot. The strategies for exploiting notions of liminality and threshold concepts remain to be fully tested and should be more explicit in our design for teaching and learning. We remain convinced by the activities of students on-line, in practice and in assignments that pearls of practice have been evidenced. The final evaluation of the program (Hillier 2008) confirms the benefits of the TQAL approach to professional development for adult literacies tutors who require a professional qualification. In feedback and reflective tasks students routinely confirmed the merits of the process both in expanding their learning and in influencing local literacies.

The context for adult literacies education in Scotland is configured by neoliberal policies, by imprecisely demarcated notions of informal education and social practices and is consequently framed by dualisms that are ideologically inconsistent. Approaches to social practices that are truly learner-centred may be subverted by the influence of didactic instruction, deficit models of literacies and the drive for certification as the primary measure of success. This however is not the regulated or hierarchical world of industry, commerce or school. Rather it is the world of loosely coupled systems in which the tutor operates at the end of a chain of command whilst engaging with local people (literacies learners) to create practice (negotiate learning). This infers a degree of discretion, choices that if made on the basis of appropriate reflection may advance critical practices. Participants on this program who adopt its principles have demonstrated the potential to build, shape and enhance future adult literacies practice collaboratively and as activist professionals.

Our approach to the program offers a mechanism for opening up the multiple meanings attached to practitioners' subjectivities. Through building collaboration, critical reflection and action inquiry we aim to render these subjectivities contingent and mobile in and against a historical hegemony that wants teachers to have a pre-defined identity as represented by powerful and dominant discourses about institutional education and learning (Zemblyas 2006:301). Our explicit approach to learning on the program is therefore to 
build on the social practices ethos and through the community of practice to create possibilities of action which include[s] the creation of new rules that nurture and advance new learning practices i.e. ways that reformulate discourse and practice (Zemblyas 2006). Thus the activist teacher suggested by Sachs (2003:92) is influential in guiding TQAL students to see themselves as part of a wider network, drawing from and contributing to partnerships reinventing their professional identity and redefining themselves as teachers. It is in the enactment of these principles that threshold concepts, troublesome knowledge and states of liminality can be processed like grit in the oyster to produce something valuable - in this case pearls of critically informed adult literacies practice.

\section{References}

Ackland, A and Wallace, D (2006) Teaching Teaching as Social Practice TQAL a professional development curriculum for social actors, paper presented at the 2006 NRDC International Conference, Nottingham, retrieved 25 June 2010 from http://www.nrdc.org.uk/content.asp? Category ID $=657 \&$ ArticleID $=863 \# 13$.

Bereiter, C and Scardamalia, M (2003) Learning to Work Creatively with Knowledge, in De Corte, E, Verschaffel, L and Entwistle, N eds, Powerful Learning Environments: Unravelling basic components and dimensions, Pergamon, Oxford, pp 55-68.

Biggs, J and Tang C (2007) Teaching for Quality Learning at University, 3rd edition, Open University Press, Maidenhead.

Boud, D (2000) Sustainable Assessment: Rethinking assessment for the learning society, Studies in Continuing Education, vol 22, no 2, pp $151-167$.

Boud, D, Solomon, N and Symes, C (2001) New Practices for New Times, in Boud, D and Solomon, N, eds, Work Based Learning: A new higher education? Open University Press, Buckingham.

Brookfield, S (2000) Adult Cognition as a Dimension of Lifelong Learning, in Field, J and Leicester, M, eds, Lifelong Learning: Education across the lifespan, Routledge-Falmer, London.

Cheetham, G and Chivers, G (2001) How Professionals Learn - the Practice! What the empirical research found, Journal of European Industrial Training, vol 25, no 5, pp 270 -292.

Claxton, G, Atkinson, T, Osborn, M and Wallace, M(eds) (2000) Liberating the Learner: Lessons for Professional Development in Education, Routledge, London

Collin, K and Valleala, M (2005) Interaction Among Employees: How does learning take place in the social communities of the workplace and 
how might such learning be supervised? Journal of Education and Work, vol 18, no 4, pp 401-420.

Cope, B, and Kalantzis, M (2003) Multiliteracies - Literacy Learning and the Design of Social futures, Routledge, Oxfordshire.

Cousin, G (2006) An Introduction to Threshold Concepts, Planet, no 17, December, pp 4-5.

Cranton, P (2006) Understanding and Promoting Transformative Learning A guide for educators of adults, 2nd edition, Jossey-Bass, San Francisco.

Davies, P, Hamilton, M and James, K (2007) Maximising the Impact of Practitioner Research - A handbook of practical advice, NRDC, London.

De Corte, E, Vershaffel, L, Entwhistle, N and van Merrienboer, J (2003) Powerful Learning Environments: Unravelling basic components and dimensions, Pergamon, Oxford.

Earl, L and Timperley, H, eds (2008) Professional Learning Conversations Challenges in using evidence for improvement, Springer, London.

Engestrom, Y (2001) Expansive Learning At Work: Toward an activity theoretical reconceptualisation, Journal of Education and Work, vol 14, no 1, pp 133-156.

Eraut, M (1994) Developing Professional Knowledge and Competence Falmer, London.

Eraut, M, Alderton, J, Cole, G, and Senker, P (1998) Learning From Other People At Work, in Coffield, F, ed, Learning at Work, Polity Press, Bristol, pp 37-48.

Evans, K, and Kersh, N (2006) Adults Learning in, for and through the Workplace: The significance of biography and experience, Paper presented at the British Educational Research Association Annual Conference, University of Warwick, 6-9 September 2006.

Freire, P (1972) Pedagogy of the Oppressed, Penguin, Harmondsworth.

Green, A and Howard, U (2007) Skills and Social Practices: Making common cause - an NRDC Policy Paper, NRDC, London

Hagar, P (2004) The Conceptualisation of Measurement of Learning, in Rainbird, H, Fuller, A and Munro, A, eds, Workplace Learning In Context, Routledge, New York, pp 242-258.

Hakkarainen, K, Palonen, T, Paavola, S, and Lehtinen, E (2004) Communities of Networked Expertise: Professional and educational perspectives, Elsevier, Amsterdam.

Hillier, Y (2008) Evaluation Report of the Pilot Teaching Qualification in Adult Literacies, unpublished report.

Illeris, K (2007) How We Learn, Routledge, Oxon.

Kirkwood, C (1990) Vulgar Eloquence - From labour to liberation, Polygon, Edinburgh. 
Land, R, Meyer, J and Smith J, eds (2008) Threshold Concepts Within the Disciplines, Sense, Rotterdam.

Lewis, C, Encisco, P, and Moje EB (2007) Reframing Sociocultural Research on Literacy - Identity, agency and power, Lawrence Erlbaum, New Jersey.

Maclachlan, K (2006) Don't Look North through Rose Tinted Spectacles: Tensions, struggles, and guiding lights in Scotland, RaPAL, vol 60, Summer, pp 32-36.

Meyer, J, and Land, R (2003) Threshold Concepts and Troublesome Knowledge: Linkages to ways of thinking and practising within the disciplines, ETL Project, Occasional report 4, retrieved 4 September 2008 from http://www.ed.ac.uk/etl/docs/ETL report4.pdf.

Meyer, J, and Land, R (2006) Overcoming Barriers to Student Understanding: Threshold concepts and troublesome knowledge, Routledge, London.

Moon, J (2006) A Handbook of Reflective and Experiential Learning Theory and practice, Routledge-Falmer, Oxon.

Paechter, C (2003) Masculinities and Femininities as Communities of Practice, Women's Studies International Forum, vol 26, no 1, pp 6977.

Papen, U (2005) Adult Literacy as Social Practice: More than skills, Routledge, London.

Sachs, J (2000) The Activist Professional, Journal of Educational Change, vol 1, no 1, pp 77-95.

Sachs, J (2003) The Activist Teaching Profession, Open University Press, Buckingham.

Saunders, M (2006) From "Organisms" to "Boundaries": The uneven development of theory narratives in education, learning and work connections, Journal of Education and Work, vol 19, no 1, February 2006, pp 1-27.

Scottish Executive (2001) Adult Literacy and Numeracy in Scotland Report, Scottish Executive, Edinburgh.

Scottish Executive (2005) An Adult Literacy And Numeracy Curriculum Framework For Scotland, Scottish Executive, Edinburgh.

Sommerlad, E (2003) Theory, research and practice - the problematic appearance of pedagogy in post-compulsory education, Journal of Adult and Continuing Education, vol 8, no 2, pp 147-164.

Tett, L, Hall, S, Maclachlan, K, Thorpe, G, Edwards, V and Garside, L (2006) Evaluation of the Scottish Adult Literacy and Numeracy Strategy - Final Report, Scottish Executive, Edinburgh.

Wenger, E (1998) Communities of Practice: Learning, meaning, and identity, Cambridge University Press, Cambridge. 
Wenger, E, McDermott, R and Snyder, W (2002) Cultivating Communities of Practice: A guide to managing knowledge, Harvard Business School, Boston.

Zemblyas, M (2006) Work-based learning, power and subjectivity: creating space for a Foucaldian research ethic Journal of Education and Work, vol 19, no 3, pp 291-303. 